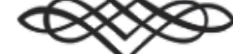

William Ospina and the narratives for the construction of a political ethic in a transition scenario

\title{
William Ospina y las narrativas para la construcción de una ética politica en un escenario de transición
}

Carlos Felipe Rúa Delgado

Universidad de San Buenaventura cfrua@usbcali.edu.co

DOI: https://doi.org/10.15366/bp2021.27.006

Bajo Palabra. II Época. № 27. Pgs: 125-142 
Recibido: 16/14/2020

Aprobado: 07/05/2021

\section{Resumen}

La identificación de los distintos problemas en la historia de Colombia y el arduo proceso de establecer un proyecto nacional, si bien ha sido tarea de muchos teóricos, no encuentra un mejor desarrollo que en la obra del escritor William Ospina. Con sus tres entregas: “¿Dónde está la franja amarilla?", "Pa' que se acabe la vaina” y "De La Habana a la Paz", en momentos distintos, el autor refleja las precariedades del Estado y, de manera analítica, elabora narrativas que instan al cambio y la transformación de la dirigencia colombiana, teniendo como cimiento elementos de la ética política cuyo proceder, hoy día, son vitales en la implementación del Acuerdo de Paz con las FARC, sinónimo de transición en el país.

Palabras clave: Acuerdo de Paz, Estado, Etica-Politica, Narrativas de cambio, Análisis.

\section{Abstract}

The identification of the different problems in the history of Colombia and the arduous process of establishing a national project, although it has been the task of many theorists, finds no better development than in the work of the writer William Ospina. With his three installments: "Where is the yellow stripe?", "To finish the pod" and "From Havana to Peace", at different moments, the author reflects the precariousness of the State and, analytically, elaborates narratives that urge to the change and transformation of the Colombian leadership, based on elements of political ethics whose actions, today, are vital in the implementation of the Peace Agreement with the FARC, synonymous with transition in the country.

Keywords: Peace Agreement, State, Ethics-Policy, Narratives of change, Analysis. 
W Illiam Ospina Buitrago (Padua, Tolima, 1954) es un reconocido escritor colombiano cuya obra literaria se ha encargado de retratar, desde asuntos coloniales y la identidad latinoamericana, hasta aspectos críticos del panorama sociopolítico en su país. Su recorrido en la literatura se ha destacado por su experticia en la construcción de ensayos, novelas, poesías y artículos periodísticos; los galardones y reconocimientos de los que ha sido merecedor dan prueba de ello. En 1982 es ganador del Premio Nacional de Ensayo de la Universidad de Nariño, Pasto, con su texto Aurelio Arturo, la palabra del hombre.; cuatro años más adelante sale a la luz su primer poemario Hilo de ideas (1986). Desde ese entonces inicia el despliegue de su carrera con ensayos tales como Aurelio Arturo (1991), Es tarde para el hombre (1994), ¿Dónde está la franja amarilla? (1996), Los nuevos centros de la esfera (2001), Pa' que se acabe la vaina (2013) y De La Habana a la paz (2016), entre otros. Entre sus poemas se hallan El país del viento (1992), ¿Con quién habla Virginia caminando hacia el agua? (1995) y Sanzetti (2018). Por último y no de menor relevancia, su compendio novelístico está conformado por las obras Ursúa (2005), El pais de la canela (2008), La serpiente sin ojos (2012), El año del verano que nunca llegó (2015) y Guayacanal (2019).

Por otra parte, las apreciaciones de escritores de talla internacional sobre sus creaciones son esenciales en la carrera del escritor colombiano; en 1996, Mario Vargas Llosa elogia el ensayo Es tarde para el hombre, definiendo el trabajo de Ospina como sinónimo de alta calidad ${ }^{1}$ y, en el 2005, Gabriel García Márquez, encuadra como mejor libro del año a su novela Ursúa 2. Por otra parte, el Premio Nacional de Poesía en 1992, el Premio Casa de las Américas en el 2003 y el Premio Rómulo Gallegos, 2009, entre otros títulos de tipo Honoris Causa, reposan en su prestigioso curso.

Una segunda parte sustancial en la producción literaria de William Ospina, encuentra lugar en la crítica social y política frente a la realidad de Colombia-basada en una suerte de progresismo-identificando los problemas desde la raíz y, a efectos de recomendación, creando sendas a través de las cuales hallar una solución de cambio y compromiso. Tal abanico de elementos encuentra lugar en ¿Dónde está la franja amarilla?, Pa' que se acabe la vaina y De La Habana a la Paz, siendo estos un análi-

\footnotetext{
'Llosa, M. V., "El canto de las sirenas", en El País, 14 de julio de 1996.

2 Redacción El Tiempo., "Perfil de William Ospina, ganador del Rómulo Gallegos", en El Tiempo, 5 de junio de 2009.
} 
sis crítico de la historia política contemporánea de Colombia, un escenario para la construcción de una ética política en el marco de los post-acuerdos con las FARC y una compilación de ensayos donde están representados el impacto de la guerra y el anhelo de paz en la construcción de la sociedad colombiana, respectivamente.

Para efectos de este trabajo, se examinará lo característico de éstas tres últimas obras, referido a dilucidar las bases narrativas diseñadas por Ospina que apuntan al avance social y político de Colombia, teniendo como panorama de observación El Acuerdo de Paz firmado con las FARC y los compromisos que de él se adquirieron, toda vez que simboliza un punto de inflexión en la historia del país y su abordaje desde una ética política prometería enormes cambios en el contexto nacional.

\section{Cronología de hechos en Colombia como base para una macro-narrativa}

El conteXto del Siglo XX colombiano para William Ospina sirve como panorama específico en la explicación de sus obras ¿Dónde está La Franja Amarilla? y Pa’ que se acabe la vaina; en ellas se da cuenta de todos los intríngulis acaecidos desde inicios del siglo XIX y sus posteriores resultados en la historia nacional, haciendo urgente recalcar el deber-ser político y cómo alcanzarlo.

En sus primeras páginas da un calificativo de avergonzada y vacilante a la sociedad colombiana: el primero en cuanto a su misma esencia, de raíces coloniales, mestizas y negras, mientras que, el segundo, tiene foco en la construcción de instituciones que persisten en ser una copia europeizada ${ }^{3}$. Revelado este imaginario arraigado en las personas, expresado a partir de una negación constante de la historia y de la riqueza étnica y cultural, se enfoca en la figura que representa el Estado tal cual está erigido, dándole un rol detonante de los males en el país; a su parecer, es un instrumento que permite a los poderosos ser los dueńos de todo, abrirles oportunidades, al tiempo que torna imposible cualquier tipo de promoción social, transformación o sensibilidad generosa sobre los más vulnerables ${ }^{4}$.

Tal carácter servil del Estado es originario del proyecto nacional concebido en el siglo $\mathrm{XIX}^{5}$, proyecto en que se apartó un amplio margen de la sociedad convirtiendo la exclusión en algo estructural. Aquí es donde tiene lugar el elemento principal de la macro-narrativa desarrollada por el Ospina de la década de los noventa, dada

\footnotetext{
${ }^{3}$ Ospina, W., ¿¿Dónde está la franja amarilla?, Penguin Random House, 2012, p. 14.

4 Ib., p. 17.

5 Según anota William Ospina "Las guerras civiles del siglo XIX derrotaron el pensamiento liberal, el radicalismo y la tradición ilustrada de los sectores democráticos, e impusieron finalmente un régimen aristocrático clerical centralizado cuya Constitución, promulgada en 1886, gobernó al país durante más de cien años.” Ospina, W., ¿Dónde está la franja amarilla?, o. c., p. 51.
} 
la partición del poder única y exclusivamente en una ardua contienda entre dos partidos políticos, liberales y conservadores, alrededor de la cual serían instituidos más de cien años de historia patria, la cual se caracteriza por censurar y violentar otro tipo de discurso e ideas de cambio.

Un antes y un después de los acontecimientos históricos del país son antecedidos por un constreñimiento masivo de la facción conservadora sobre la liberal a finales del siglo XIX. Bajo una amalgama infranqueable entre el Estado y la Iglesia, el poder conservador se arraigó en cada una de las esferas de vida de aquél entonces. Según afirma Ospina "Esto dio origen a tremendos cuadros de violencia familiar y de intolerancia social, a un enorme irrespeto por las creencias ajenas, y a la tendencia persistente a considerar toda disidencia y rebeldía como un fenómeno religioso." ${ }^{6}$ Tal condición fortificó el germen de violencia y fanatismo partidario en Colombia, cuyos últimos recipientes fueron los sectores sociales no acogidos por el Estado. Entrado el siglo XX la inconformidad popular y las revueltas sindicales aumentan, fruto de los privilegios cada vez más visibles que el Estado le otorgaba a las altas clases sociales, poniendo en jaque a la hegemonía conservadora, gestando así un impulso a la facción liberal. ${ }^{7} \mathrm{Al}$ contrario de amainar la violencia, se ciñó sobre la vida rural y sus pobladores.

Lo hasta aquí explicado supone un conflicto visceral entre nacionales: tomar las riendas del país según ideales de una facción política y la negación del otro son sus características, de él sacan mayor ventaja los privilegiados sociales sea de uno u otro bando. Ante esa dicotomía, Ospina ensalza la figura de Jorge Eliecer Gaitán, caudillo liberal pero que "entendió que el principal enemigo de la sociedad colombiana era ese bipartidismo aristocrático cuyos jefes formaban en realidad un solo partido de dos caras, hecho para saquear al país y beneficiarse de él a espaldas de las mayorías [...]" ${ }^{8}$. En este sentido, observa en Gaitán la instauración del proyecto nacional desde una "tercera vía", abordando así por sus ideas e iniciativas constantemente durante la Obra, siendo la columna vertebral de esa primera narrativa, fundamentada en la apertura política hacia otras ideas y experiencias, hacia el reconocimiento del otro y su discurso, como la base para ampliar las funciones y el cobijo del Estado sobre la población en general. ${ }^{9}$

La clase dirigente colombiana, al observar con infinito escozor a las multitudes partidarias del movimiento gaitanista, se expresó con una violencia intensificada en

\footnotetext{
${ }^{6}$ Ibidem.

7 Ib., p. 52.

8 Ib., p. 52-53.

9 Para el entonces, William Ospina afirmaba que "En Colombia hoy no se trata de construir un Estado infinitamente poderoso, intervencionista y molesto, ya que la sociedad por fortuna ha aprendido vivir sin él, sino de desmontar la iniquidad de un Estado antipopular y abusivo, cambiándolo por una administración simple pero
} 
el campo y las difamaciones sobre el caudillo. Por último, como es bien sabido, tal empresa de cambio político es atenuada debido al asesinato en 1948 del afamado caudillo, iniciando la gigantesca contrarrevolución que marcaría el destino del país en los cincuenta ańos venideros. ${ }^{10}$ Ante esto, el autor colombiano afirma que:

Esta contrarrevolución tuvo tres etapas, cada una de ellas peor que la anterior. La primera fue el asesinato del caudillo, que provocó el incendio de la capital. La segunda fue la Violencia de los años cincuenta, que despobló los campesinos de Colombia e hizo crecer dramáticamente las ciudades con millones de desplazados arrojados a la miseria. La tercera fue el pacto aristocrático del Frente Nacional, mediante el cual los instigadores de la violencia se beneficiaron de ella y se repartieron el poder durante veinte ańos, proscribiendo toda oposición, cerrando el camino de acceso a la riqueza para las clases medias emprendedoras, y manteniendo a los pobres en condiciones de extremo desamparo mientras acrecentaban hasta lo obsceno sus propios capitales ${ }^{11}$.

Tal descripción de la violencia y el conflicto en la historia nacional, recalca, en demasía, los elementos que esa primera narrativa desarrollada por el tolimense en su obra ¿Dónde está la franja amarilla? insta a cambiar, a saber: la violencia entre facciones políticas, el acallamiento de cualquier discurso e idea que atente contra la estabilidad de la élite, el "ninguneo" de la población más vulnerable y la creación sistémica de obstáculos al progreso de la clase media. El llamado conclusivo de Ospina es claro: se hace urgente abandonar la idea y el proyecto bipartidista, liberal-conservador, ella solo ha negado constantemente el reparto de la riqueza, la imposibilidad manifiesta en forjar un Proyecto Nacional, la cohibición por intereses velados frente al desarrollo industrial amplio, silenciando todo tipo de belleza natural y humana que Colombia tiene (o tenía) por ofrecer al mundo entero. ${ }^{12}$ Por si no quedara claro, la unión de todas las experiencias políticas y étnico-sociales funge como ejercicio angular en la gesta de ese gran Proyecto Nacional, hasta ahora no desarrollado, situación que amenaza con separar cada vez más lo alejado entre sí y que pone en contexto la recomendación de William al afirmar:

que sólo tomando posesión de ese lenguaje, múltiple y cohesionador, que le dé un nuevo sentido a la nación y a su historia, podremos llegar a constituir un movimiento capaz, no de reclamar ni de pedir sino de provocar los grandes cambios sociales que requiere el país $[\ldots]^{13}$.

respetable y activa, que le sirva a la sociedad para desplegar sus posibilidades y para enfrentar la rica e indócil naturaleza que nos ha correspondido" Ib., p. 33.

10 Ib., p. 54.

11 Ibidem.

12 Ib., p. 81.

13 Ib., p. 86. 
La publicación de Pa que se acabe la vaina, en el dos mil trece, diecisiete años después de escrita ¿Dónde está la franja amarilla?, tiene lugar en un escenario enrarecido: el proceso de la constituyente del 91 y su Carta Magna ha logrado ampliar el espectro de partidos políticos que se ofrecen como representantes de la voz del pueblo en la democracia colombiana. Si bien otras cosas pueden ser mencionadas, es esta la más cercana a aquella primera narrativa elaborada por el autor; además, la etapa inicial de las conversaciones entre el Gobierno y las FARC-EP-guerrilla más antigua del país y del continente- buscando salida al conflicto armado, daba luces de esa incursión en la apertura política y discursiva. Según esto, Ospina se va a enfocar principalmente en demostrar cómo a través de la historia, la falta de oportunidades y la negación colonial de los máximos dirigentes en aceptarse como hijos de esta tierra ${ }^{14}$, ha instaurado una especie de tragicomedia nacional donde el protagonista es víctima de sus propios actos.

Desde el ideario del Estado como máquina de exclusivismos, el sentido de lo público se torna cada vez más pesimista en la generalidad ciudadana. En adición, se arraiga la cultura de la ilegalidad, producto del castigo o resarcimiento de los daños no ejemplarizantes para el grueso social. Según afirma el autor: Basta que se instaure sobre la sociedad un sistema de privilegios y exclusiones, para que los ciudadanos empiecen a sentir que la ley no es garantía sino trampa. ${ }^{15}$ Es de aclarar que la ilegalidad, ante un Estado paquidérmico y elitista, se ha ensañado por ser la única salida orquestada de la población en manos de éste último, ante la carencia y el impedimento del progreso. A la ecuación se suma el factor violento entre compatriotas impulsado por las clases dirigentes, motivo por el cual el colombiano deja de verse como parte de una comunidad, vulnerable al vaivén decisorio de las políticas tomadas por las grandes instituciones ${ }^{16}$.

¿Cómo negar que desde la independencia el país se ha inmerso en un cuadro violento y al parecer sin salida alguna? Se pregunta entre líneas Ospina, describiendo detalladamente esa historia de la segunda mitad del siglo XX en Colombia, marcada por una época conocida como la Violencia ${ }^{17}$, seguida de un pacto entre las únicas facciones políticas de aquél entonces bajo el nombre de Frente Nacional ${ }^{18}$, siendo simultánea a los dieciséis años de su duración (1958-1974) la conforma-

\footnotetext{
${ }^{14}$ Ya afirma el autor: Algo antiguo y persistente ha conspirado para que los colombianos siempre nos sintiéramos una suerte de extranjeros en nuestra propia patria, y a la vez para que no aprendiéramos a vernos como conciudadanos. Ospina, W., Pa que se acabe la vaina, Editorial Planeta, 2013, p. 42.

15 Ib., p. 36.

16 Ib., p. 44.

${ }_{17}$ Con 598 registros de asaltos y masacres entre 1946-1966. Ib., p. 122.

${ }_{18}$ De acuerdo con el autor: El llamado Frente Nacional no tenía como propósito salvar al país maltratado sino garantizar la continuidad en el poder de las castas que habían dominado a Colombia durante más de cien años, y que la seguirían dominando durante el resto del siglo. Ib., p. 148.
} 
ción de guerrillas campesinas ${ }^{19}$ y movimientos revolucionarios como respuesta a las falencias del progreso y la movilidad social. En este sentido, la exclusión de un amplio margen de la sociedad comenzó a bullir bajo expresiones notorias de delincuencia en las ciudades y surgimiento de grupos guerrilleros. Sobre estos sucesos, una segunda narrativa empieza a tomar forma: en adición a la anterior, procura centrarse en que la incorporación a un Proyecto Nacional y el pensar en un Estado para todos, y no para unos cuantos, funge como catalizador del progreso, situación que impondría y haría lógica la adhesión del ciudadano a la cultura de la legalidad.

El surgimiento de guerrillas urbanas tales como el M-19, producto de un fraude electoral ${ }^{20}$, la narcotización de la economía ilegal colombiana y el tinte de violencia que produjo tanto en el campo como en la ciudad desde $1974^{21}$, la pauperización de la industria nacional, la aparición del fenómeno del paramilitarismo en los campos colombianos como respuesta contraguerrilla ${ }^{22}$ y desbocada sobre la población rural, todo eso inmerso en una burbuja de corrupción naciente, guarda como elemento de partida la ineptitud de un Estado al que todos los ciudadanos, a sangre y fuerza, habían confiado sus más altas expectativas de vida; su compromiso por ese pacto social y el respeto de las instituciones, se precipitaba amenazando no perdurar dadas las condiciones de vida tan distantes entre los sectores de la sociedad: el Estado era infinito para la clase privilegiada, amenazante e inseguro situación contraria para las clases media y pobre.

En aras de afinar su consigna el autor establece que "Colombia tendrá que emprender una reparación profunda, tendrá que brindar a tantos seres destruidos por la falta de oportunidades, la posibilidad de un nuevo comienzo" ${ }^{23}$. Así, la centralidad del Estado como figura clave en el progreso de los individuos y que, a través de sus instituciones, juega un papel protagónico en el quéhacer de sus ciudadanos, es una necesidad que plantea William Ospina ante el desarrollo de Colombia como país y como nación.

La implementación del Acuerdo de Paz como un espacio de transición desde la ética política y las narrativas de William Ospina

El SACUdón DE LA HISTORIA POLÍTiCa colombiana en la última década del siglo tuvo lugar con la negociación entre el Gobierno Nacional y las FARC-EP, ambas

\footnotetext{
${ }_{19}$ Escribe como nota Ospina: Los primeros guerrilleros comunistas eran en realidad liberales traicionados, campesinos que le dijeron no a la orden de emigrar a la ciudad [...]. Ib., p. 185.

${ }^{20}$ Ib., p. 190.

${ }^{21}$ Ib., p. 200.

${ }^{22}$ Ib., p. 227.

${ }^{23}$ Ib., p. 234.
} 
partes sentadas en La Habana, Cuba, y con diversos ojos de la comunidad internacional puestos sobre el proceso iniciado en el 2012, con firma exitosa en el 2016. En resumen, la renuncia al proyecto de las FARC, iniciado en 1962, optando por seguir las reglas del juego interpuestas por la democracia y el compromiso del Gobierno en garantizar su incorporación a la vida civil y política, y la creación de sanciones más allá de la ley penal ${ }^{24}$. Tal suceso despertó, si bien no en todas las partes del escenario político en el país, un descontento o júbilo; la segunda administración de Juan Manuel Santos reavivó el componente negociador del Estado con una de las partes mayormente involucradas en el conflicto, cuya duración ya alcanzaba más de 50 años. La situación no fue ajena a William Ospina, quien para el año en que se finiquitaría el pacto construido entre el Gobierno y las FARC, publica su obra De La Habana a la Paz, encontrando allí confluencia sus ya explicadas narrativas, y vislumbrándose como oportunidad única de cambio y transformación del país.

Entre sus páginas es descrito el acompañamiento crítico que presta a la fase de negociaciones; haciendo figurar las experiencias del pasado, establece una serie de recomendaciones para la construcción del Acuerdo, y alertando que, una vez más, tal intento de pacificación podría perecer a causa de una lucha de egos entre la misma clase dirigente representada en ese entonces por Juan Manuel Santos y Álvaro Uribe Vélez. Correspondiente a eso Ospina afirma que:

Ahora dos de los pilares de ese precario proceso de recuperación de legitimidad institucional, Álvaro Uribe y Juan Manuel Santos, se están trenzando en un conflicto que podría desencadenar la nueva violencia colombiana. No porque cualquiera de los dos pretenda desatar un baño de sangre, sino porque en Colombia es muy fácil que los desacuerdos de las élites se conviertan en desangre de las multitudes humildes ${ }^{25}$.

Tal proyecto de reconciliación, tímido en principio entre ambas partes, significó el comienzo de aquél nuevo modo en que la elite mandataria pasaría a entender el país. El Estado se estaba alejando del modelo bélico y represivo que lo caracterizaba, pasando a comprender una narrativa, entre miles, existentes sobre la violencia en Colombia. Así, era presentado un momento de oportunidad para quienes nunca habían sido involucrados por el Estado en la construcción del país, tarea pendiente hasta el día de hoy.

Por ello, el desarrollo del Acuerdo resuelve disponer de una ética política o ética sobre lo público a través del cual sea orientado y ajustado. De acuerdo con Restrepo, la idea que tenemos sobre modernidad y sobre el hombre moderno, aquél

\footnotetext{
${ }^{24}$ Melo Orlando, J., "Resumen del Acuerdo de Paz", en Revista de Economía Institucional, Universidad Externado de Colombia, núm. 35, 2016, p. 319.

25 Ospina, W., De la Habana a la Paz, Penguin Random House, 2016, p. 143.
} 
moralmente autónomo y dispuesto a realizar el bien como imperativo máximo, es aquella impuesta y recreada en la Europa del Renacimiento, desligada de una cosmovisión netamente religiosa característica de la Edad Media ${ }^{26}$. Tal figura entonces, destaca por su carácter contestatario y, especialmente, por reflejar la superposición de la razón sobre la fe "antigua", proceso imperante durante la época, ilustrado en aparatosos sistemas racionales constituidos y esa nueva fe ciega en la capacidad transformadora del hombre ${ }^{27}$.No obstante, como toda parte contestataria, su impulso fue perdiéndose en el transcurso de los siglos a medida que el orden eclesiástico europeo se fue disolviendo paulatinamente y la razón, debido a los grandes enfrentamientos entre hombres y el creciente yugo de lo económico sobre la libertad, se tornó cada vez más frágil. ${ }^{28}$ Así, el ideario transferido hacia América Latina y arraigado únicamente a finales del siglo XIX, era estéril y con síntomas de vacuidad en su lugar de origen.

La gran crítica adjudicada a todos los países de este lado del Atlántico (con algunas excepciones) es no haber constituido un Estado sólido, en donde el bienestar y la justicia sean para todos, alargando la falta de legitimidad de la cultura legal abordada por Ospina. Las tensiones desplegadas por una falta de representatividad ejecutiva, o, caso contrario, un modelo autoritario, resultan en un conflicto al borde de la violencia y el terror extremos sustentadas por un conjunto de ideas pertenecientes a tan solo una pequeña parte de la población; Colombia es uno de estos tipos de sociedad, antecedida por disputas entre sus nacionales a merced de discursos hegemónicos internos y con resultados nefastos para la cohesión social. Sobre estos factores es que el Estado Social de Derecho, clasificación que enarbola la Carta Magna colombiana del 91, ha encontrado diversos problemas para desarrollar su razón de ser, una vez la población dista de ser incluida en las transformaciones lentas del Estado condicionando la justicia social del modelo democrático.

La base ética del Estado Social descansa, según afirma Cortina en "incluir en el sistema de derechos fundamentales no sólo las libertades clásicas, sino también los derechos económicos, sociales y culturales." ${ }^{29}$ Por tal motivo, el hacer-interventor del Estado debe orientarse a la concesión de aquellos derechos, comprendidos en el marco de una vida digna y llevadera para el ser humano. A pesar del avance mostrado por el Estado Colombiano en tal asunto, los retos planteados en la im-

\footnotetext{
${ }^{26}$ Restrepo, L. A., "Ética para una sociedad en conflicto", en Cortina, A; Ferry, L; García, M; Gómez, M; Goyard, S; Hoyos, G; Krombach, H; Moon, J; Motta, C; Nino, C.S; Restrepo, L.A; De Sousa Santos, B., Ética y Conflicto Lecturas para una transición democrática, Colombia, Tercer Mundo Editores, 1995, pp. 81-110.

27 Ospina, W., Es tarde para el hombre, Random House Mondadori, 2012, p. 18.

${ }_{28}$ Restrepo, L.A., "Ética para una sociedad en conflicto", op. cit., pp. 89-92.

${ }^{29}$ Cortina, A., "Presupuestos morales del Estado Social de Derecho", en Cortina, A; Ferry, L; García, M; Gómez, M; Goyard, S; Hoyos, G; Krombach, H; Moon, J; Motta, C; Nino, C.S; Restrepo, L.A; De Sousa Santos, B.,
} 
plementación del Acuerdo repercuten en la ampliación de ese carácter ético al que su connotación "Social de Derecho" lo ata, sobre la reincorporación a la vida civil de los ex-combatientes de las FARC. El sobrellevar tal asunto debe coincidir en alcanzar ese lugar común de la ética y la política: el bien ${ }^{30}$ alejado de cualquier tipo de audacia en donde el poder económico siga persistiendo sobre el político y ocasionando una mayor ruptura de la ética, como característica del continente. ${ }^{31}$ Ambas narrativas de William Ospina encajan perfectamente en ésta discusión teórica, especialmente en el llamado a la interpelación de nuevos discursos y la alternatividad sobre el modelo de país- en ¿Dónde está la Franja Amarilla?-añadiendo esa figura de un Estado para todos-presente en Pa que se acabe la vaina-; ambos fungen como narrativas éticas sobre lo político y la construcción de un Proyecto Nacional. En De La Habana a la Paz persiste su intención, esta vez, en un momento único en la historia de Colombia; su advertencia sobre hacer la paz con uno de los actores del conflicto traspasa las fronteras de la paz militar, y aborda otros elementos de la vida en comunidad, a saber y como manifiesta:

La paz exige superar todo eso. La paz no puede ser apenas un pacto de élites armadas. Ese acuerdo debe ser un comienzo, pero todos deberíamos estar construyendo desde ya ese relato de complejidad y solidaridad colectiva. Más aún, acaso nunca veremos de verdad los acuerdos si no ocurre ese despertar ciudadano que, sin privarse de mirar al pasado y de exigir la indemnización de las víctimas, ponga el énfasis en el futuro, en inventar la normalidad desconocida y en adivinar la Colombia que nos ha negado la guerra. ${ }^{32}$

En efecto, la visión de esa paz estructural, denota un cambio en la élite y el fin del modelo político de lucha de roles, imperante a lo largo de la historia nacional. Asimismo, urge su ajuste a una ética sin fines electoreros, tan criticada por Corti$\mathrm{na}^{33}$, dado que la animosidad de su realización debería estar exenta de cualquier fin político en un periodo de administración y sobre el cual se inste a las masas para acaparar votos. Sobre esta idea, Ospina analiza sus factores e insta a la oportunidad de ampliar la participación en el marco de la democracia únicamente alcanzable si el Estado busca disminuir las brechas que pueden persistir de cara a una violencia física o estructural. En el caso de Colombia, el Acuerdo, conlleva a analizar tanto

Ética y Conflicto Lecturas para una transición democrática, Colombia, Tercer Mundo Editores, 1995, pp. 185-206.

${ }^{30}$ Caldera Serrano, A., "Ética y política”, en Caldera Serrano, A. (ed.), Ética y Política, Managua, Nicaragua, Fundación Friedrich Ebert, 2003, pp. 9-27.

31 Ib., p. 14.

32 Ospina, W., De la Habana a la Paz, op. cit., p. 276.

33 Cortina, A., "Presupuestos morales del Estado Social de Derecho", en Cortina, A; Ferry, L; García, M; Gómez, M; Goyard, S; Hoyos, G; Krombach, H; Moon, J; Motta, C; Nino, C.S; Restrepo, L.A; De Sousa Santos, B., Ética y Conflicto Lecturas para una transición democrática, op. cit., p.197. 
a la parte "legitima", como a la "subversiva", desde su carácter obstaculizador en la aparición de nuevas ideas sobre la vida política del país; indisponiendo la esencialidad argumentativa de los regímenes democráticos ${ }^{34}$. Por su parte, sobre la facultad de todo Estado Social de Derecho, como es proclamado Colombia, su operatividad ética tiene lugar en la satisfacción de necesidades básicas y mínimos vitales para la población; para afirmar ello, se parte de la idea de una ética política que oriente y prescriba el qué hacer público, referente a la toma de decisiones ${ }^{35} \mathrm{~A}$ condición de ello, sobre la implementación del Acuerdo recaen toda una serie de observaciones y recomendaciones éticas, políticas y sociales, nacionales e internacionales, que el Estado, siendo representado por un gobierno de turno, debería recopilar y prestar atención.

Para el 2018, dos ańos posteriores a la firma de lo pactado, los resultados ya se notaban: entre un año de implementación y de dejación de las armas por parte de las FARC, el Centro de Recursos para el Análisis de Conflictos (CERAC) afirmaba que durante el 2017 no se registró ningún tipo de muerte en combate, sea desde la fuerza pública, guerrilla de las FARC y civiles ${ }^{36}$. Existiendo otros grupos guerrilleros (tales como el ELN o el EPL), tal información elevó las más altas expectativas sobre lo firmado, especialmente para aquellos inmersos en la ya acostumbrada violencia rural. Consecuencia de esto, la época electoral del 2018 para instaurar el gobierno del siguiente cuatrienio (2018-2022) tuvo como eje vertebral la voluntad política para respetar lo pactado en La Habana, y fomentar su implementación. Triunfando Iván Duque Márquez, perteneciente al partido político Centro Democrático, partido opositor del Acuerdo, el ojo crítico nacional e internacional instó a que, el ahora presidente, mostrara compromiso en adelantar lo acordado con la extinta guerrilla de las FARC.

En el ecuador de su mandato, la violencia en Colombia, si bien no ha dejado de presentar bajas que afectan a las partes tradicionalmente comprometidas, ha tomado tintes políticos y organizativos al incidir en aquellos que promueven el cumplimiento de los acuerdos, la apertura democrática en la sociedad, la alternatividad del discurso político, el empoderamiento de las comunidades rurales y urbanas menos favorecidas, etc. De acuerdo con el CERAC, entre el 2018 y 2019,

\footnotetext{
${ }^{34}$ Ante esto, Adela Cortina sostiene que la participación de los interlocutores efectivos o virtuales, sobre la creación de normas en los modelos democráticos de sociedad, es una de las condiciones clave sine qua non su estabilidad estaría en juego. Cortina, A., "Razón Comunicativa y responsabilidad solidaria", Ediciones Sígueme, 1995, p. 181.

${ }^{35}$ Lucena Cid, I. V., "Ética y política: Algunos principios para el buen gobierno", en Revista Internacional de Pensamiento Politico, Universidad Pablo Olavide, (2017), p.450.

${ }^{36}$ Véase más en Colombia2020., "La reducción de muertes en el conflicto después del acuerdo con las Farc", El Espectador, 23 de junio de 2018. Disponible en https://www.elespectador.com/colombia2020/pais/la-reduccion-de-muertes-en-el-conflicto-despues-del-acuerdo-con-las-farc-articulo-856819
} 
han sido registrados más de 333 casos de muertes de líderes sociales o comunitarios, activistas políticos, personas en proceso de reincorporación, defensores de derechos humanos ${ }^{37}$ o relacionadas con violencia política ${ }^{38}$. A corte de febrero de 2020 se añaden 35 víctimas más, dando casi un promedio de un asesinado por día ${ }^{39}$. Todo este compendio de dramáticas cifras desdibujan la fuerza del Estado, poniendo en líneas su voluntad por fortalecer la apertura inclusiva argumentativa y discursiva que caracteriza a los regímenes democráticos. Sobre estos resultados, organizaciones internacionales de alto nivel, tal como Naciones Unidas, suscitan un eco más profundo sobre la situación.

El último informe público de la Misión de Verificación de las Naciones Unidas en Colombia, perteneciente al Consejo de Seguridad de la misma organización, sobre la implementación del Acuerdo de Paz denota mayor preocupación: la resolución de las controversias entre ambas partes se ha convertido en una puja de voluntades; el Gobierno, por su parte, señala que las FARC no han contribuido al proceso mientras que, las FARC, acusan al Gobierno de no tomar las medidas suficientes en materia de seguridad para la reincorporación de los excombatientes, amenazando la integridad del Acuerdo ${ }^{40}$. Al mismo tiempo, la sustitución de cultivos ilícitos, los enfrentamientos con el ELN, las garantías de seguridad para excombatientes y para las comunidades, defensores y defensoras de los derechos humanos y líderes sociales, se han convertido en el foco trascendental y arraigado de la violencia en el país, toda vez que la misión verificó 77 homicidios de excombatientes en el 2019, comparándolo con los 65 y 31 casos registrados en 2018 y 2017 respectivamente, 86 asesinatos de defensores y defensoras de derechos humanos para el último año, y la presencia del mencionado grupo guerrillero en departamentos como el Chocó, Norte de Santander, Arauca y Nariño, históricamente marcados por la poca presencia del Estado. ${ }^{41}$ El comportamiento de los hechos gira sobre elementos relacionados con la tenencia de la tierra, la economía ilegal y su impacto sobre la en la apertura del discurso político.

37 Centro de Recursos para el Análisis de Conflictos, "Monitor de Violencia Política en Colombia”, CERAC, 2020, p. 1.

38 De acuerdo con el CERAC, la violencia política debe entenderse como "todo evento en el que ocurre un daño intencional causado contra individuos, grupos o comunidades de personas que tiene como finalidad afectar las preferencias políticas, los niveles de representación o la toma de decisiones colectivas." Centro de Recursos para el Análisis de Conflictos., "Violencia política letal se disparó en enero de 2018". CERAC, 2018.

39 Centro de Recursos para el Análisis de Conflictos., "Monitor de Violencia Política en Colombia”, op. cit., p. 2.

${ }^{40}$ Misión de Verificación de las Naciones Unidas en Colombia. "Informe del Secretario General", Consejo de Seguridad, Naciones Unidas, 26 de diciembre de 2019, p. 2.

${ }^{41}$ Misión de Verificación de las Naciones Unidas en Colombia. "Informe del Secretario General”, op. cit., pp. 5-11. 
En materia de derechos humanos parece no escampar; ya alega el Alto Comisionado de las Naciones Unidas para los Derechos Humanos en su último informe de febrero de 2020 la importancia de continuar con la implementación del Acuerdo de Paz, en tanto supone a largo y mediano plazo el resarcimiento de daños a las víctimas y el disfrute general de los derechos humanos ${ }^{42}$; no obstante, su preocupación incrementa según los 108 homicidios de personas defensoras de derechos humanos, registrados en 2019, de los cuales, como se indica, un $75 \%$ ocurrió en zonas rurales, el $86 \%$ en municipios con una pobreza multidimensional por encima de la media nacional, y el $91 \%$ y $98 \%$, en municipios con homicidios producto de violencia endémica y con presencia de grupos violentos y criminales, respectivamente ${ }^{43}$. Sobre estos cuatro panoramas se destaca la falta de presencia del Estado expresada en institucionalidad y fortalecimiento de la misma: su ilegitimidad, producto de esa deuda histórica del proyecto nacional sobre ciertos territorios, derivada en condiciones de extrema pobreza y búsqueda de la ilegalidad como única salida rentable, tiene imagen en los cuadros de violencia que el Alto Comisionado denuncia. Una salida buscada por el gobierno de turno ha sido la militarización, medida que en otras ocasiones se ha intentado y sus resultados demuestran no ser sostenibles en el tiempo; frente a esto afirma el Alto Comisionado que:

Los esfuerzos para establecer una presencia integral del Estado, particularmente de autoridades civiles, incluyendo la Fiscalía General de la Nación y la policía, fueron insuficientes, en particular en las zonas rurales. Las cinco "Zonas Estratégicas de Intervención Integral” establecidas por el Gobierno a través del Decreto 2278 de 2019 fueron creadas para atender este vacío. Sin embargo, el ACNUDH observó que la presencia estatal en estas zonas continúa siendo predominantemente militar y el avance para establecer una mayor presencia de autoridades civiles ha sido lento ${ }^{44}$.

Conforme a esto, si el involucramiento de las fuerzas de orden público es la única manifestación del Estado se atenúa cualquier intento civil e integral por resolver los problemas de naturaleza estructural. Paralelamente al documento del Alto Comisionado, el informe de Human Rights Watch sobre la situación en Colombia, para el año 2018, identifica en los grupos guerrilleros y delincuenciales aquellos que siguen instigando a la violencia en el país, y, con zozobra, la implicación de integrantes activos del ejército nacional en asesinatos extrajudiciales, cuya investi-

\footnotetext{
42 Alto Comisionado de las Naciones Unidas para los Derechos Humanos en Colombia, "Situación de los derechos humanos en Colombia", Naciones Unidas, 26 de febrero de 2020, p. 2.

43 Ib., p. 5.

44 Ib., p.4.
} 
gación se ha visto dificultada derivando en un oscuro panorama de impunidad e ilegitimidad de la institución ${ }^{45}$.

Con estos acontecimientos sobre la mesa, es posible afirmar que el conflicto en Colombia tiende a perpetuarse, merced de una falta de voluntad política, obedeciendo a un conjunto de ideas sectarios. Si bien el Acuerdo de Paz con la extinta guerrilla de las FARC no es una solución holística al problema, trasciende como apertura al modelo democrático de participación política e inclusión a la vida civil de una de las partes; fallar en su implementación sería demostrar, una vez más, los inconvenientes que tiene la clase dirigente de Colombia por edificar un proyecto nacional y, cobijar en sus funciones, esa quimera de infortunios producto del Estado exclusivista desenmascarado y criticado por William Ospina.

\section{Reflexiones finales}

En la obra William Ospina, transcurren distintos acontecimientos que han marcado la vida social y política de Colombia. Desde una mirada analítica y literaria, el autor recoge precisos instantes del llamado "descubrimiento" de américa, centrándose en establecer que gran parte de los conflictos y fragilidad de la sociedad colombiana, yacen en el proyecto independentista del siglo XIX, producto de una lucha visceral entre egos de próceres y facciones políticas. En el siglo XX, el país no logra despegar y se posterga la idea de una modernidad de la razón aumentando la brecha social y económica. Hasta la primera mitad de éste siglo, Ospina destaca que los obstáculos interpuestos tanto a la apertura del discurso político, como al surgimiento de ideas diferentes a las congregadas bajo la dicotomía liberales-conservadores, representa la gran deuda del Estado frente a la población civil.

Sin dejar a un lado esta premisa, su análisis alrededor de la década de los 70 y una historia política más contemporánea de Colombia, deja entrever los motivos por los cuales la violencia incrementa con la aparición de las guerrillas y grupos al margen de la ley, alejando consigo un acceso a las oportunidades y tornando a la ilegalidad como único espacio de florecimiento y éxito disponible; ejemplo más claro es el del narcotráfico y los grandes capos de la droga. A sabiendas de lo anterior, la poca presencia del Estado, caracterizado por servir más a la clase privilegiada, se convierte en la segunda gran definición otorgada por el escritor colombiano: como una especie de serpiente que se come su propia cola, la clase dirigente se ha encargado

$\overline{45}$ Human Rights Watch, “Colombia. Eventos de 2018”, Human Rights Watch, 2019. 
de construir un escenario de auto-destrucción, haciendo urgente una alternativa al modelo de mando.

Con un Acuerdo de Paz a cuestas, son muchos los ojos puestos sobre Colombia y sus mandatarios. Los esfuerzos por implementar lo pactado, traen consigo elementos incisivos del estudio de la política desde la ética, correspondiendo así con un deber-ser del accionar en lo público y el buen gobierno, donde prevalezca los intereses de la mayoría en aras de arraigar aquel modelo democrático del cual se jacta la clase dirigente. La participación en la construcción del país y, principalmente, del proyecto nacional, debe ser invitación extendida y posibilitada a cada una de las partes de la comunidad, tales como la sociedad civil, la academia, el sector oficial y privado. Únicamente a partir de esa confluencia de ideas, en donde se expongan las más altas expectativas de los distintos proyectos de vida, el Estado será una cuestión de todos, destacando su deber-ser garantista en materia de derechos y creación de oportunidades. Lo identificado por Ospina, albergando estos elementos descriptivos, teóricos y analíticos, no debe ser pasado por alto; al contrario, plantea un esquema de estudio para el periodo de transición del conflicto con una de las partes en Colombia. 


\section{REFERENCIAS BIBLIOGRÁFICAS}

Alto Comisionado de las Naciones Unidas para los Derechos Humanos en Colombia, "Situación de los derechos humanos en Colombia", Naciones Unidas, 26 de febrero de 2020, Disponible en https://www.hchr.org.co/documentoseinformes/informes/altocomisionado/informe-anual-2019-ES.pdf

Caldera Serrano, A., "Ética y política", en Caldera Serrano, A. (ed.), Ética y Politica, Managua, Nicaragua, Fundación Friedrich Ebert, 2003. Disponible en https://www.elespectador.com/colombia2020/pais/la-reduccion-de-muertesen-el-conflicto-despues-del-acuerdo-con-las-farc-articulo-856819

Centro de Recursos para el Análisis de Conflictos, "Violencia política letal se disparó en enero de 2018”, CERAC, 2018, Disponible en https://www.cerac. org.co/es/1\%C3\%ADneas-de-investigaci\%C3\%B3n/analisis-conflicto/violencia-pol\%C3\%ADtica-letal-se-dispar\%C3\%B3-en-enero-de-2018.html

Centro de Recursos para el Análisis de Conflictos, "Monitor de Violencia Política en Colombia", CERAC, 2020.

Colombia2020, "La reducción de muertes en el conflicto después del acuerdo con las Farc”, El Espectador, 23 de junio de 2018.

Cortina, A., "Razón Comunicativa y responsabilidad solidaria", Ediciones Sígueme, 1995

Cortina, A., "Presupuestos morales del Estado Social de Derecho", en Cortina, A; Ferry, L; García, M; Gómez, M; Goyard, S; Hoyos, G; Krombach, H; Moon, J; Motta, C; Nino, C. S; Restrepo, L. A; De Sousa Santos, B., Ética y Conflicto Lecturas para una transición democrática, Colombia, Tercer Mundo Editores, 1995.

Human Rights Watch, “Colombia. Eventos de 2018”, Human Rights Watch, 2019. Disponible en https://www.hrw.org/es/world-report/2019/country-chapters/326041

Llosa, M. V., "El canto de las sirenas", en El País, 14 de julio de 1996. Disponible en https://elpais.com/diario/1996/07/14/opinion/837295208_850215.html

Lucena Cid, I. V., "Ética y política: Algunos principios para el buen gobierno", en Revista Internacional de Pensamiento Político, Universidad Pablo Olavide, 2017. 
Melo Orlando, J., "Resumen del Acuerdo de Paz", en Revista de Economía Institucional, Universidad Externado de Colombia, núm. 35,2016.

Misión de Verificación de las Naciones Unidas en Colombia, "Informe del Secretario General", Consejo de Seguridad, Naciones Unidas, 26 de diciembre de 2019.

Ospina, W., ¿¿Dónde está la franja amarilla?, Penguin Random House, 2012.

Ospina, W., Es tarde para el hombre, Random House Mondadori, 2012.

Ospina, W., Pa que se acabe la vaina, Editorial Planeta, 2013.

Ospina, W., De la Habana a la Paz, Penguin Random House, 2016.

Redacción El Tiempo, "Perfil de William Ospina, ganador del Rómulo Gallegos", en El Tiempo, 5 de junio de 2009. Disponible en https://www.eltiempo. com/archivo/documento/CMS-5372607

Restrepo, L. A., "Ética para una sociedad en conflicto", en Cortina, A; Ferry, L; García, M; Gómez, M; Goyard, S; HOYOS, G; Krombach, H; Moon, J; Motta, C; Nino, C. S; Restrepo, L. A; De Sousa Santos, B., Ética y Conflicto Lecturas para una transición democrática, Colombia, Tercer Mundo Editores, 1995.

DOI: https://doi.org/10.15366/bp2021.27.006

Bajo Palabra. II Época. No 27. Pgs: 125-142 